\title{
On-line Processing of "Pop-Out" Words in Spoken French Dialogues
}

\author{
Cyrille Magne $^{1}$, Corine Astésano', Anne Lacheret-Dujour ${ }^{2}$, \\ Michel Morel ${ }^{2}$, Kai Alter ${ }^{3}$, and Mireille Besson ${ }^{1}$
}

\begin{abstract}
Highlighting relevant information in a discourse context is a major aim of spoken language communication. Prosodic cues such as focal prominences are used to fulfill this aim through the pragmatic function of prosody. To determine whether listeners make on-line use of focal prominences to build coherent representations of the informational structure of the utterances, we used the brain event-related potential (ERP) method. Short dialogues composed of a question and an answer were presented auditorily. The design of the experiment allowed us to examine precisely the time course of the processing of prosodic patterns of sentence-medial or -final words in the answer. These patterns were either congruous or incongruous with regard to the pragmatic context introduced by the question. Furthermore, the ERP effects were compared for words with or without focal
\end{abstract}

\section{INTRODUCTION}

Imagine that you hear the following short dialogue: The mother asks "Did he give his fiancée a ring or a bracelet?" and her daughter answers "He gave a RING to his fiancée," stressing the relevant information. In this discourse context, the word RING "pops out" from the string of words in the daughter's answer. In other words, speakers can choose to emphasize the relevant information (i.e., the "figure," here brought out by the word RING) ${ }^{1}$ so that it stands out from the rest of the message already given in the question (i.e., the "ground," which is the context of communication, or mental space, shared by both speakers; Fauconnier, 1984). ${ }^{2}$ In this case, this emphasis is achieved by means of prosodic variations.

Prosody can broadly be defined at the abstract phonological level as the patterns of stress and intonation in a spoken language, and at the concrete acoustic level by several parameters: fundamental frequency $\left(\mathrm{F}_{0}\right)$, intensity, duration, and spectral characteristics. Prosody con-

\footnotetext{
${ }^{1}$ INCM-CNRS, Marseille, France ${ }^{2}$ Université de Caen, Caen, France, ${ }^{3} \mathrm{Max}$ Planck Institute of Cognitive Neuroscience, Leipzig, Germany
}

prominences. Results showed that pragmatically congruous and incongruous prosodic patterns elicit clear differences in the ERPs, which were largely modulated in latency and polarity by their position within the answer. By showing that prosodic patterns are processed on-line by listeners in order to understand the informational structure of the message, the present results demonstrate the psychobiological validity of the pragmatic concept of focus, expressed via prosodic cues. Moreover, the functional significance of the positive-going effects found sentence medially and negative-going effects found sentence finally is discussed. Whereas the former may reflect the processing of surprising and task-relevant prosodic patterns, the latter may reflect the integration problems encountered in extracting the overall informational structure of the sentence.

veys both emotional and linguistic information in spoken language. The linguistic function of prosody operates at both the lexical (e.g., meter) and structural levels (stress and intonation patterns). Moreover, the structural function of prosody in utterance parsing and hierarchical organization can be seen at both the syntactic (phrasing) and pragmatic levels (e.g., Di Cristo, 1999; Hirst \& Di Cristo, 1998; Cutler, Dahan, \& van Donselaar, 1997, for a comprehensive review of the functions of prosody). From a pragmatic point of view, speakers use prosody to organize their message, and listeners use it to identify relevant information in an utterance. Communication is optimal when information is successfully conveyed; that is, when within a general given context and background shared knowledge (common mental space) speakers successfully bring to the foreground the relevant new information they want to convey.

The process by which new information becomes cognitively relevant is known as focus. There are two approaches to focus: bottom-up and top-down. In the bottom-up approach, prosodic variations in the speech signal are interpreted phonologically to build up a linguistic representation. Conversely, in the top-down approach, which we adopt, focus is a pragmatic con- 
cept that can be realized either through the combination of syntactic construction and prosodic cues or through prosodic cues only. Indeed, in many languages, and typically in spoken French, focus can be marked through syntactic constructions (change in word order, use of specific morphemes, i.e., grammatical focus). For example, to the question "Qui a mangé le gateau?" [Who ate the cake?], speakers will tend to answer "C'est Marie qui a mangé le gâteau" [It's Marie who ate the cake]. The syntactic construction "C'est Marie" bears the focus, whereas the second clause is part of the ground or shared knowledge. However, there are also cases, which are the objects of study here, in which focus is not expressed via syntactic means but through prosodic variations, so that prosodically prominent elements stand out from the rest of the sentence ("MARIE a mangé le gâteau"/"MARIE ate the cake") and highlight the relevant information of the utterance. Focus can be broad when all parts of an utterance are equally informative or narrow when a specific lexical item is given additional weight (Ladd, 1980, 1991).

In the present experiment, we manipulated a particular type of narrow focus, contrastive focus, to specifically analyze the prosodic marking of focus. Contrastive focus induces an exclusive selection in a paradigmatic class (Di Cristo, 1998). As exemplified by the dialogue at the beginning of this article, the question ("Did he give his fiancée a ring or a bracelet?") introduces a paradigmatic opposition between the words "ring" and "bracelet," which is resolved by a prosodic prominence on the relevant word in the answer. Indeed, in French, speakers generally use a global rising/falling intonation pattern to realize contrastive focus. This pattern is characterized phonetically by extra pitch prominence, longer duration and greater $\mathrm{F}_{0}$ excursions and intensity mainly on the first syllable (Astésano, Magne, et al., 2004; Astésano, 2001; Lacheret-Dujour \& Beaugendre, 1999; Di Cristo, 1998; Pasdeloup, 1990; Séguinot, 1976). Contrastive focus also induces the prosodic reconfiguration of surrounding words, and relative prominence is altered. Thus, phonetically, intensity and pitch patterns are reduced around the focal element; more specifically, pitch prominences are reduced in amplitude before focus and postfocal elements are produced with a slightly declining, low $\mathrm{F}_{0}$ pattern without pitch prominence (downstepped tonal pattern; Astésano, Magne, et al., 2004; Di Cristo \& Jankowski, 1999).

The specific aim of our study was to determine whether listeners make on-line use of prosodic prominences to process relevant information in a discourse context. Indeed, although the prosodic marking of focus is an important aspect of spoken language comprehension that has largely been studied by linguists, phoneticians, and psycholinguists, it has not been much studied by neurolinguists. Directly related to our concerns, Most and Saltz (1979), in one of the first studies within the large phonetics literature on the intonation-discourse interface, asked listeners to pair "wh" questions with their appropriate answers. They found that the position of the accentuation (focal accent) in the answer largely determined the listener's pairing choices. More recently, Birch and Clifton (1995) also manipulated the prosodic-pragmatic congruence of question-answer pairs; they demonstrated that accenting new/relevant information and de-accenting given/background information in the answers led to faster comprehension judgments and higher prosodic appropriateness ratings than when the reverse was used. Thus, appropriate accentuation clearly seems to facilitate speech comprehension (see also Terken \& Nooteboom, 1987; Bock \& Mazzella, 1983; Brown, 1983).

However, as noted by Venditti and Hirschberg (2003), off-line comprehension tasks have most often been used in this field of research, so on-line measures are strongly needed. Thus, the aim here is to shed light on the psychophysiological underpinnings of the prosodic marking of focus by using a method that allows for investigation of the precise time course of spoken language comprehension as it unfolds in real time: the brain event-related potential (ERP) method. Before going into the details of the experiment, we briefly describe previous relevant results in the literature on the electrophysiology of language processing.

\section{Electrophysiological Correlates of Language Processing}

Over the past 20 years, the ERP literature has mainly been focused on the electrophysiological correlates of semantic and syntactic processing rather than prosodic and pragmatic processing. The first language-related component to be discovered was the N400 (Kutas \& Hillyard, 1980), a negative component peaking around $400 \mathrm{msec}$ post critical word onset. Since then, numerous results have been reported that are in line with the general interpretation after which the $\mathrm{N} 400$ reflects semantic processing and the integration of word meaning in sentence or discourse contexts (see Besson, Magne, \& Regnault, 2004; Brown \& Hagoort, 1999, for reviews). Regarding syntax-related ERP effects, violations of phrase structure, word agreement, verb tense, and subcategorization elicit late positive components, peaking around $600 \mathrm{msec}$ after the onset of the critical word (i.e., the P600 component; Hagoort, Brown, \& Groothusen, 1993; Osterhout \& Holcomb, 1992). Word category and morphosyntactic violations also elicit the occurrence of negative components, peaking around 300-500 msec and with maximum amplitude over left anterior regions (i.e., the left anterior negativity or LAN; Hahne \& Friederici, 1999; Gunter, Stowe, \& Mulder, 1997). 
More recently, several studies have been designed to examine the neurophysiological basis of some of the aspects of prosody described above. For instance, Schirmer, Kotz, and Friederici (2002) investigated the emotional function of prosody by manipulating the intonation contour of sentences (e.g., "Yesterday, she had her final exam") that were spoken with either happy or sad intonation. Sentences were followed by a visually presented target word. Results showed that the N400 component was smaller for visual target words that matched (e.g., "success" following a sentence spoken with a happy intonation) compared with those that did not match sentence prosody (e.g., "success" following a sad intonation). These results were taken to illustrate the influence of emotional prosody on semantic processing (Besson, Magne, \& Schön, 2002).

Böcker, Bastiaansen, Vroomen, Brunia, and De Gelder (1999) examined the lexical function of prosody through the rhythmic properties (i.e., metrical stress) of spoken words in Dutch. Participants listened to sequences of bisyllabic Dutch words, which started with either a weak-strong (12\% of the Dutch lexicon) or a strongweak stress pattern. Results showed that the infrequent weak-strong stress patterns elicited a larger negativity (denoted as N325) than the more frequent strong-weak stress patterns. The authors concluded that the N325 reflects metrical stress extraction from the acoustic signal. This conclusion was, however, challenged by the results of Friedrich, Alter, and Kotz (2001) showing that when the first vowel was controlled for duration, amplitude, and vowel quality, infrequent initially unstressed German words elicit an enlarged P2 component rather than an N325 component. Thus, the occurrence of an N325 may reflect differences in the intrinsic characteristics of the vowels rather than a more general metrical stress extraction process.

In a seminal series of experiments, Steinhauer, Alter, and Friederici (1999) investigated the structural function of prosody at the phrase level. They clearly demonstrated that listeners make on-line use of prosodic cues to parse the syntactic structure of utterances. Specifically, their results revealed that a positive component, closure positive shift (CPS), was elicited at prosodic boundaries. Moreover, in a follow-up experiment, using the same material as in the first study but presented in written form, they were able to show that commas also elicit CPS-like components (Steinhauer \& Friederici, 2001). Thus, commas may be used as visual markers for prosodic boundaries and the CPS may not be specific to auditory processing. Note, however, that it is also possible that silent reading involves the construction of mental prosody (Fodor, 2002).

Finally, Astésano, Besson, and Alter (2004) investigated the modality function of prosody by studying the relationship between semantic and prosodic processing; auditorily presented sentences were semantically and/or prosodically congruous or incongruous. Prosodic incongruities were created by cross-splicing the beginning of statements (declarative sentences) with the end of questions (interrogative sentences) and vice versa. Results showed that a left temporoparietal positive component (P800) was associated with prosodic mismatch. Moreover, the finding that the P800 component was larger when the sentences were semantically incongruous than congruous suggests that at least some aspects of semantic and prosodic processing may be interactive.

\section{The Present Study}

As this brief review of the literature shows, only a few neurophysiological studies have been dedicated to the study of prosodic processing using the ERP method. Furthermore, whereas previous studies were focused on the lexical, structural, or semantic functions of prosody at the word or sentence levels, the specific aim of the present experiment was to study contrastive focus at the discourse level. In keeping with previous psycholinguistic experiments and to control for contextual influences, short dialogues composed of a question and an answer were created to induce specific expectancy regarding the position of focal contrastive accents in the answer. In addition, for each answer (e.g., "He gave a ring to his fiancée"), two versions of the question were created. In one version ("Did he give his fiancée a ring or a bracelet?"), focal contrastive accents were expected on the medial word "ring" of the answer, whereas in the other version ("Did he give a ring to his fiancée or his sister?"), focal contrastive accents were expected on the final word of the answer "fiancée." Therefore, the coherence of the dialogue depended on the accented word in the answer. By crossing the presentation of the two types of questions (contrastive focus expected on medial or on final word) with the two types of answers (contrastive focus realized on medial word or on final word), we created four experimental conditions (see Table 1).

In the two coherent dialogue conditions ("expected focal accent"), contrastive focal accents are realized on the relevant information, that is, on the expected medial $\left(\mathrm{MF}_{0}\right)$ or final $\left(\mathrm{M}_{0} \mathrm{~F}\right)$ words. By contrast, in the two incoherent dialogue conditions ("inappropriate focal accents"), contrastive focal accents are realized on medial words $\left({ }^{*} \mathrm{MF}_{0}\right)$ when expected on final words, and realized on final words $\left({ }^{*} \mathrm{M}_{0} \mathrm{~F}\right)$ when expected on medial words. The originality of this design is that the same word in the answer (e.g., ring or fiancée) can be pragmatically congruent or not according to the preceding question and, consequently, it can be used as its own control. If focal contrastive accents are processed on-line by listeners to build up a coherent representation of the given/new informational structure of the dialogue, we expect pragmatically congruous and incongruous focal 
Table 1. Examples of Stimuli in the Four Experimental Conditions

\begin{tabular}{|c|c|c|c|}
\hline Conditions & $\begin{array}{c}\text { Sentence-Medial } \\
\text { Word }\end{array}$ & $\begin{array}{c}\text { Sentence-Final } \\
\text { Word }\end{array}$ & Example \\
\hline $\mathrm{MF}_{0}$ & Expected focus & Expected no focus & $\begin{array}{l}\text { A-t-il donné une bague ou un bracelet à sa fiancée? } \\
\text { (Did he give his fiancée a ring or a bracelet?) } \\
\text { Il a donné une bague à sa fiancée. } \\
\text { (He gave a ring to his fiancée.) }\end{array}$ \\
\hline$* \mathrm{MF}_{0}$ & Inappropriate accent & Missing accent & $\begin{array}{l}\text { A-t-il donné une bague à sa fiancée ou à sa soeur? } \\
\text { (Did he give a ring to his fiancée or his sister?) } \\
\text { Il a donné une bague à sa fiancée. } \\
\text { (He gave a ring to his fiancée.) }\end{array}$ \\
\hline $\mathrm{M}_{0} \mathrm{~F}$ & Expected no focus & Expected focus & $\begin{array}{l}\text { A-t-il donné une bague à sa fiancée ou à sa soeur? } \\
\text { (Did he give a ring to his fiancée or his sister?) } \\
\text { Il a donné une bague à sa fiancée. } \\
\text { (He gave a ring to his fiancée.) }\end{array}$ \\
\hline$* \mathrm{M}_{0} \mathrm{~F}$ & Missing accent & Inappropriate accent & $\begin{array}{l}\text { A-t-il donné une bague ou un bracelet à sa fiancée? } \\
\text { (Did he give his fiancée a ring or a bracelet?) } \\
\text { Il a donné une bague à sa fiancée. } \\
\text { (He gave a ring to his fiancée.) }\end{array}$ \\
\hline
\end{tabular}

Note that across participants, the very same sentences were used in the four conditions. They were pragmatically congruous or incongruous only in relation to the preceding questions.

accents to elicit different ERP patterns. Based on results obtained by Astésano, Besson, et al. (2004) and Steinhauer et al. (1999), showing that prosodic processing is generally associated with increased positivity, and because highlighting irrelevant information should create a surprise for the listener, we predicted that inappropriate focal accents $\left(* \mathrm{MF}_{0}\right.$ and $\left.* \mathrm{M}_{0} \mathrm{~F}\right)$ should elicit larger positive components compared with the same focal accents when they are pragmatically congruous $\left(\mathrm{MF}_{0}\right.$ and $\mathrm{M}_{0} \mathrm{~F}$ conditions). However, if the prosodic marking of focus directly supports the integration of words within the discourse context, a larger N400 component may also be elicited by pragmatically incongruous words, so as to obtain only an N400, as reported by Schirmer et al. (2002), or an N400 followed by a positivity, as reported by Steinhauer et al. (1999).

In addition, this design also allows us to examine the electrophysiological consequences of a missing focal accent. Indeed, when an inappropriate accent is present on medial words $\left(* \mathrm{MF}_{0}\right)$, this implies that there is no accent on final words although one is expected. Similarly, an inappropriate accent on final words $\left(* \mathrm{M}_{0} \mathrm{~F}\right)$ implies that no accent is present on medial words whereas one is expected. We predicted that the absence of a focal accent when one is expected (e.g., fiancée in $* \mathrm{MF}_{0}$ and ring in $* \mathrm{M}_{0} \mathrm{~F}$ ) should also be surprising (as inappropriate focal accents, although not necessarily to the same extent) and elicit an increased positivity compared with the same words when no focal accent is expected (e.g., fiancée in conditions $\mathrm{MF}_{0}$ and ring in $\mathrm{M}_{0} \mathrm{~F}$ ). Note also that the absence of prosodic marking may hinder comprehension and that, conse- quently, an N400, possibly followed by a positivity, may be generated.

As mentioned above, words with and without focal contrastive accents differ in their acoustic characteristics. It was therefore of interest to determine whether such differences would influence early ERP components. Moreover, by comparing the pragmatic congruity effects for words with and without focal contrastive accents, it was possible to address the issue of whether pragmatic congruity effects are similar or different for words with different acoustic properties.

Finally, it was of interest to study the influence of the position of the focused words within the sentence (medial vs. final). Indeed, several results in the literature point to the importance of word position on semantic, syntactic, and pragmatic effects. For instance, Van Petten and Kutas (1990) showed that the sentence-final congruous words, which are typically more expected than the first or medial words because of the building up of a sentence context, are associated with smaller N400 components. By contrast, morphosyntactic violations typically elicit larger negative components when they are located sentence medially than sentence finally (Osterhout, 1997). Because different types of integration processes (semantic, syntactic, pragmatic) are likely to occur at the end of the target sentence (i.e., answers), it may well be that the electrophysiological effects of pragmatic violations, realized through inappropriate or missing focal accents, would differ as a function of their medial or final positions within the sentence.

To summarize, this design allows us to investigate the time course of contextually induced predictions related 
to prosodic marking of focus when they are fulfilled or not. These effects can be compared with the effects for words with or without focal accents when they are located sentence medially or sentence finally within the target answer.

\section{RESULTS}

\section{Coherence Judgment}

According to the preceding question context, participants judged $95 \%$ of the answers with expected focal accents $\left(\mathrm{MF}_{0}\right.$ and $\left.\mathrm{M}_{0} \mathrm{~F}\right)$ as acceptable and $92 \%$ of the answers with inappropriate focal accents $\left({ }^{*} \mathrm{MF}_{0}\right.$ and $\left.* \mathrm{M}_{0} \mathrm{~F}\right)$ as unacceptable. These results clearly demonstrate that participants were sensitive to the pragmatic congruity of the focal contrastive accents.

\section{Electrophysiological Data}

\section{Visual Inspection}

As can be seen clearly in Figures $1 \mathrm{~A}$ and $2 \mathrm{~A}$, the pragmatic congruity effect (i.e., the difference between words with or without pragmatically congruous patterns and words with or without pragmatically incongruous accents) is reversed in polarity for sentence medial and final words. Indeed, whereas pragmatically incongruous accents elicit an increased positivity when occurring sentence medially, they elicit an increased negativity when occurring sentence finally. Moreover, this pragmatic congruity effect seems to start earlier for final (around $150 \mathrm{msec}$ ) than medial words (around $300 \mathrm{msec}$ ). However, note that for sentence-medial words, a small positive pragmatic congruity effect develops at left frontal sites in the 150- to 300-msec latency band and increases in amplitude and extends over centroparietal sites from 300 to $1050 \mathrm{msec}$ (see Figure 1B). For sentence-final words, a clear negative effect develops early over midline frontal sites in the 50to 150 - and 150- to 300-msec latency bands and then extends over centroparietal sites from 300 to $1050 \mathrm{msec}$ (see Figure 2B).

\section{Statistical Analyses}

General analyses of variance. In order to examine these ERP effects in more detail, mean amplitude of the ERP waveforms were measured in successive 150-msec latency windows from focal accent onset ${ }^{3}$ until $1050 \mathrm{msec}$ afterward, relative to a 150-msec baseline. Analyses of variance (ANOVAs) were computed separately for midline and lateral electrodes, and the $p$ values reported below were adjusted with the GreenhouseGeisser epsilon correction for nonsphericity. The uncorrected degrees of freedom and the probability level after correction are reported. ANOVAs for midline sites included Position of focal accents (on medial vs. final

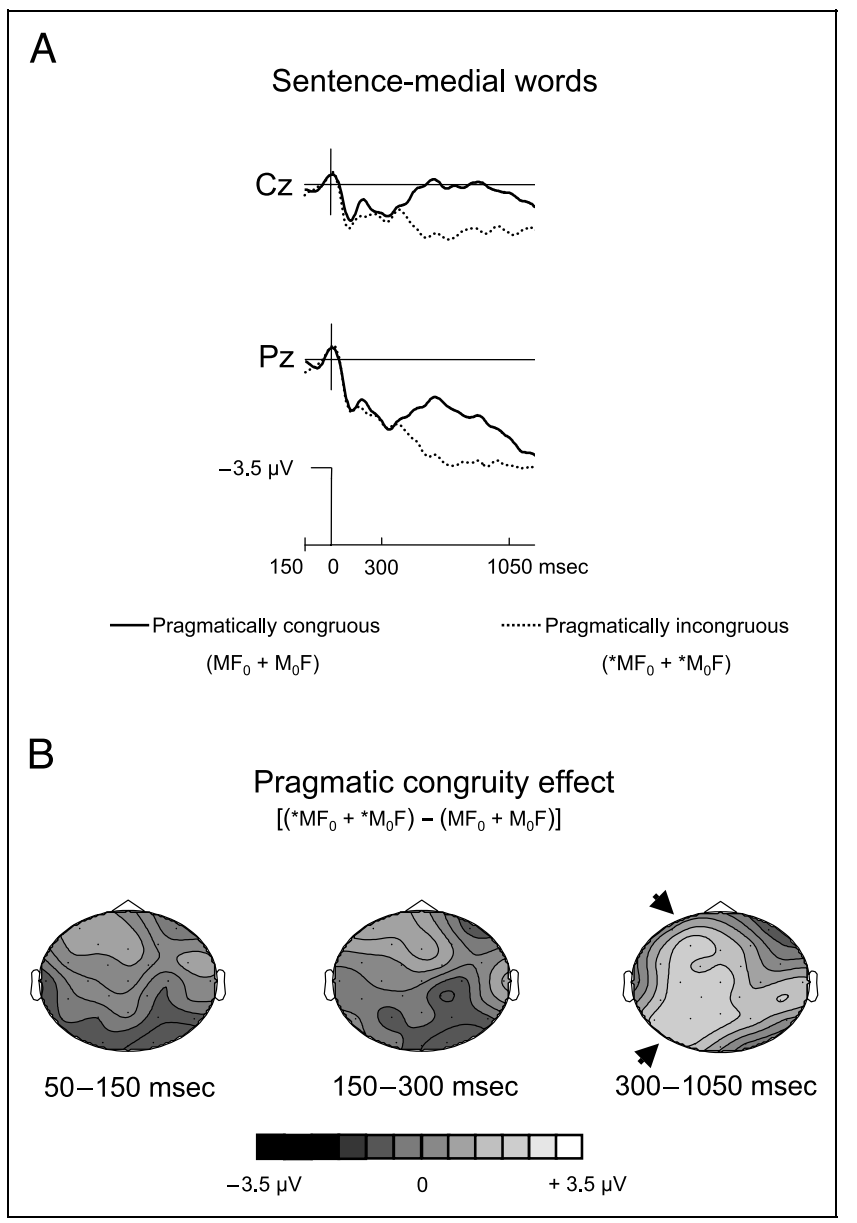

Figure 1. Middle words. (A) Averaged electrophysiological data, recorded from 16 participants, and time locked to the onset of pragmatically congruous (solid trace) or pragmatically incongruous (dotted trace) prosodic patterns, at central $(\mathrm{Cz})$ and parietal $(\mathrm{Pz})$ electrodes. On this figure and the followings ones, the amplitude (in microvolts) is in the ordinate (negative up) and the time (in milliseconds) in the abscissa. Note that ERPs in the $\mathrm{MF}_{0}$ (expected focal accent) and $\mathrm{M}_{0} \mathrm{~F}$ (expected no focal accent) conditions were averaged together to form the ERPs to pragmatically congruous patterns and that the ERPs in the $* \mathrm{MF}_{0}$ (inappropriate focal accent) and $* \mathrm{M}_{0} \mathrm{~F}$ (missing focal accents) conditions were averaged together to form the ERPs to pragmatically incongruous patterns. (B) Topographic maps of the pragmatic congruity effect. Mean amplitude differences between pragmatically incongruous prosodic patterns $\left({ }^{*} \mathrm{MF}_{0}+{ }^{*} \mathrm{M}_{0} \mathrm{~F}\right)$ and pragmatically congruous prosodic patterns $\left(\mathrm{MF}_{0}+\mathrm{M}_{0} \mathrm{~F}\right)$ in the 50- to $150-, 150-$ to $300-$, and 300- to $1050-\mathrm{msec}$ latency windows.

words), Congruity (pragmatically congruous vs. incongruous contrastive focal accents), Focus (focal accents present vs. absent), and Electrodes (Fz, Cz, Pz, Oz) as factors. To test for the distribution of ERP effects, ANOVAs were also computed for lateral electrodes, using six regions of interest (ROIs): left and right anterior (F3, F7, FC5 and F4, F8, Fc6), left and right centrotemporal (Fc1, C3, Cp1 and Fc2, C4, Cp2), and left and right temporoparietal ( $\mathrm{Cp} 5, \mathrm{P} 3, \mathrm{~T} 5$ and $\mathrm{Cp} 6, \mathrm{P} 4$, T6). These ANOVAs included Position of focal accents 


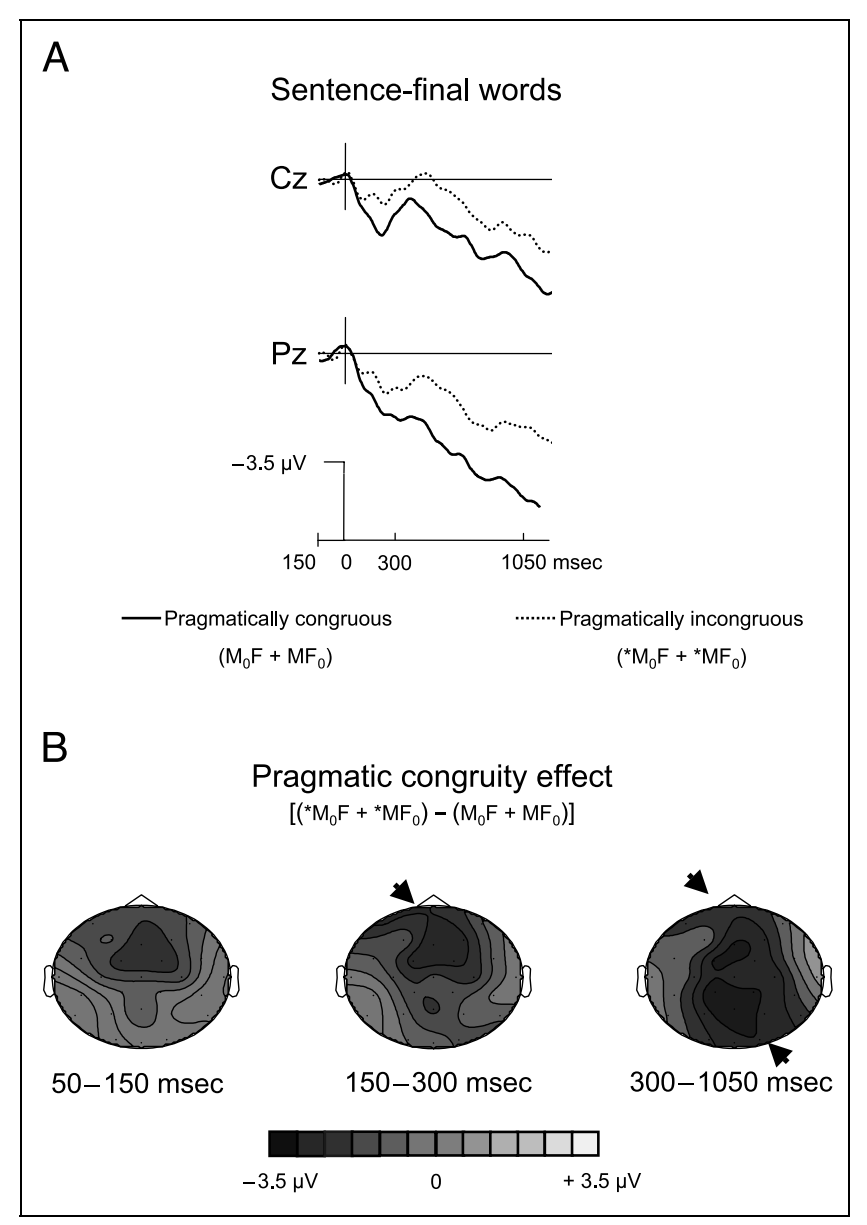

Figure 2. Final words. (A) Averaged electrophysiological data, recorded from 16 participants, and time locked to the onset of pragmatically congruous (solid trace) or pragmatically incongruous (dotted trace) prosodic patterns, at central $(\mathrm{Cz})$ and parietal $(\mathrm{Pz})$ electrodes. Note that ERPs in the $\mathrm{M}_{0} \mathrm{~F}$ (expected focal accent) and $\mathrm{MF}_{0}$ (expected no focal accent) conditions were averaged together to form the ERPs to pragmatically congruous patterns and that the ERPs in the $* \mathrm{M}_{0} \mathrm{~F}$ (inappropriate focal accent) and $* \mathrm{MF}_{0}$ (missing focal accents) conditions were averaged together to form the ERPs to pragmatically incongruous patterns. (B) Topographic maps of the pragmatic congruity effect. Mean amplitude differences between pragmatically incongruous prosodic patterns $\left({ }^{*} \mathrm{M}_{0} \mathrm{~F}+{ }^{*} \mathrm{MF}_{0}\right)$ and pragmatically congruous prosodic patterns $\left(\mathrm{M}_{0} \mathrm{~F}+\mathrm{MF}_{0}\right)$ in the 50 to $150-$, 150- to 300-, and 300- to 1050-msec latency windows.

(on medial vs. final words), Congruity (pragmatically congruous vs. incongruous contrastive focal accents), and Focus (focal accent present vs. absent), as well as Hemispheres (left vs. right), Localization (anterior, centrotemporal, and temporoparietal), and Electrodes (three for each ROI), as factors.

Results of analyses in the 50- to 150-msec latency window revealed no main effect of Position, Congruity, or Focus and no significant interaction between the effects of these three factors. By contrast, in the 150to 300-msec latency window, results revealed a significant Position by Congruity interaction at midline electrodes, $F(1,15)=7.49, p<.01$. Between 300 and
$1050 \mathrm{msec}$, results revealed a main effect of Position at lateral electrodes, $F(1,15)=5.53, p<.03$, and a significant Position by Congruity interaction at both midline, $F(1,15)=34.48, p<.001$, and lateral electrodes, $F(1,15)=14.42, p<.001$.

To better understand the nature of these interactions, separate analyses were conducted for focal accents on medial and final words.

Medial words. As can be seen in Figure 3 (left column), sentence-medial words with pragmatically incongruous prosodic patterns elicited significantly more positive ERPs than words with pragmatically congruous prosodic patterns. This positive effect was found independently of the presence or absence of focal accents (see Figure $3 \mathrm{~A}$ and $\mathrm{B}$ ) and was statistically significant in the 450- to 600-, 600- to 750-, and 750- to 900-msec latency windows (main effect of Congruity at both midline and lateral electrodes, with no main effect of presence/absence of Focus and no Congruity by presence/absence of Focus interaction; see Tables 2 and 3 for a summary of statistical analyses).

Interestingly, this positive effect started earlier for words with than without focal accents at frontal locations (significant Congruity by presence/absence of Focus by Localization with significant differences between inappropriate and congruous focal accents over the frontal regions in the 300- to 450-msec latency window: $* \mathrm{MF}_{0}$ vs. $\mathrm{MF}_{0} ; F(1,15)=4.78, p=.04$, and no differences in the same latency window for words without accents: ${ }^{*} \mathrm{M}_{0} \mathrm{~F}$ vs. $\mathrm{M}_{0} \mathrm{~F} ; F<1$; see Figure 4). Moreover, for words with focal accent, the positive effect still had a frontal distribution in the 450- to 600-msec latency windows and then a frontoparietal scalp distribution between 600 and $750 \mathrm{msec}$ (see Figure 4A). For words without focal accents, the positive effect had a centroparietal distribution in both the 450- to 600- and 600- to 750-msec latency windows (see Figure 4B; marginally significant Congruity by presence/absence of Focus by Localization interaction in both latency bands, see Table 3). Between 900 and $1050 \mathrm{msec}$, the positive effect was still present at midline electrodes only (see Table 2).

Finally, it is interesting to note that words with pragmatically congruous prosodic patterns do not differ as a function of the presence or absence of focal accent (see Figure 3C). Similarly, words with pragmatically incongruous prosodic patterns do not differ as a function of the presence or absence of focal accent (see Figure 3D).

Final word. As can be seen in Figure 5 (left column) and in contrast with the results for medial words, sentence-final words with pragmatically incongruous prosodic patterns elicited more negative ERPs than words with pragmatically congruous prosodic patterns. This negative effect was found independently of the 
Figure 3. Pragmatic congruity effect for middle words (A) with focal accents and (B) without focal accents. Effect of the presence/ absence of focal accents for pragmatically $(\mathrm{C})$ congruous and (D) incongruous prosodic patterns.

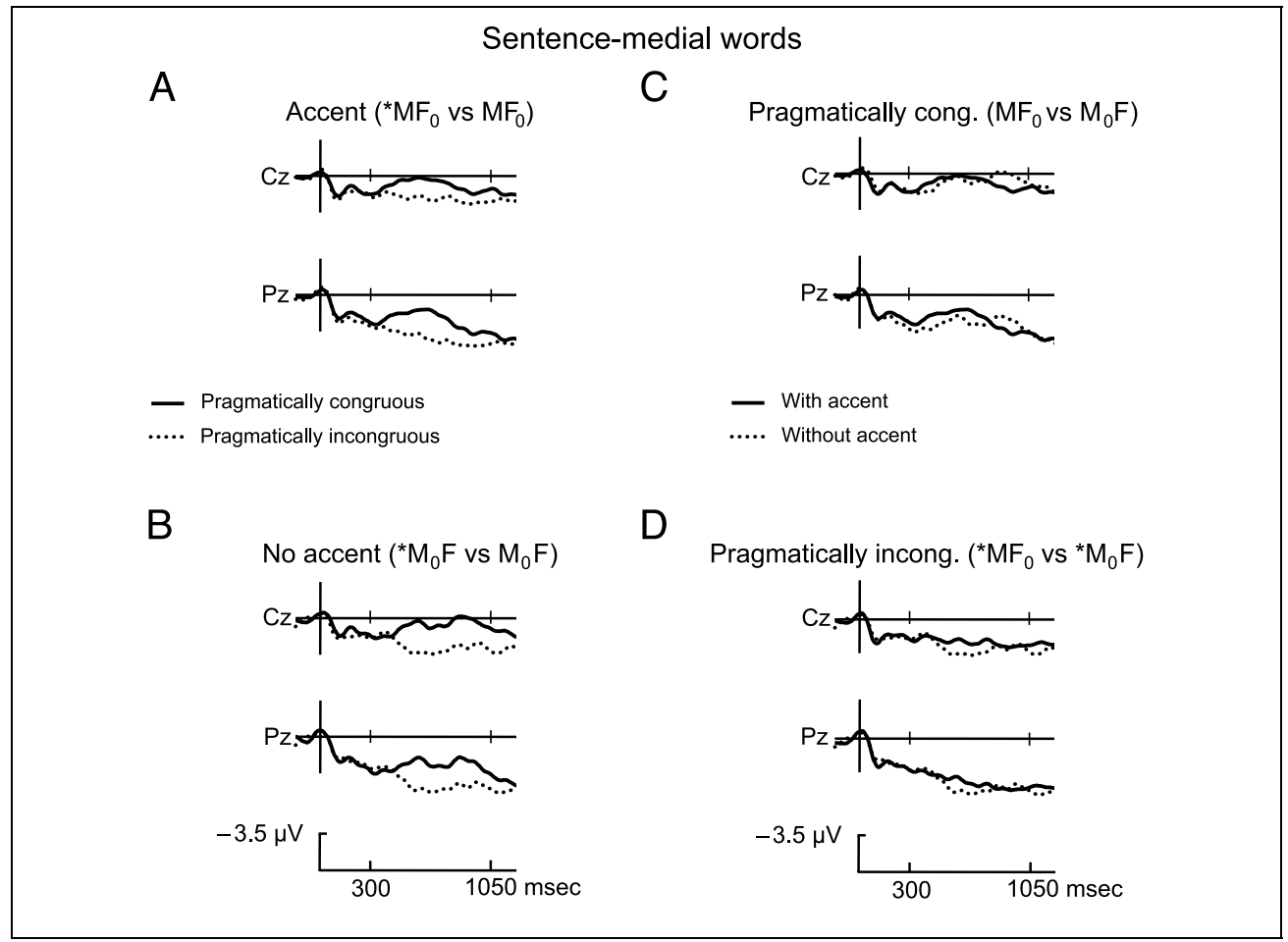

presence or absence of focal accents (see Figure $5 \mathrm{~A}$ and B) and was statistically significant in the successive 150-msec latency windows, between 150 and $1050 \mathrm{msec}$, considered for analysis (main effect of Congruity; see Tables 4 and 5; and Figure 6).

Interestingly, the negative effect was largest frontally in the 150- to 300-msec latency window (Congruity by Electrode interaction in the midline electrodes analysis with no main effect of presence/absence of Focus and no Congruity by presence/absence of Focus interaction, see Tables 4 and 5). It was largely distributed across the scalp between 300 and $750 \mathrm{msec}$ (no Congruity by
Localization interaction) and showed a more centroparietal distribution between 750 and 1,050 msec, as revealed by the analysis of lateral electrodes (Congruity by Localization interaction; see Table 5).

Finally, as can be seen in Figure 5 (right column), no differences were found for pragmatically congruous words with $\left(\mathrm{M}_{0} \mathrm{~F}\right)$ or without $\left(\mathrm{MF}_{0}\right)$ focal accents (Figure 5C). Similarly, no differences were found for pragmatically incongruous words with $\left(* \mathrm{M}_{0} \mathrm{~F}\right)$ or without $\left(* \mathrm{MF}_{0}\right)$ focal accents (Figure $\left.5 \mathrm{D}\right)$. Consequently, neither the main effect of presence/absence of Focus nor the Congruity by presence/absence of Focus inter-

Table 2. Sentence-Medial Word ( $F$ Values for the ANOVAs at Midline Electrodes)

\begin{tabular}{|c|c|c|c|c|c|c|c|}
\hline \multirow[b]{2}{*}{ Factors } & \multirow[b]{2}{*}{$d f$} & \multicolumn{6}{|c|}{ Latency Windows (msec) } \\
\hline & & $150-300$ & $300-450$ & $450-600$ & $600-750$ & $750-900$ & $900-1050$ \\
\hline $\mathrm{C}$ & 1.15 & - & - & $13.03^{* *}$ & $24.38 * * *$ & $9.8^{* *}$ & $4.76^{*}$ \\
\hline $\mathrm{F}$ & 1.15 & - & - & - & - & - & - \\
\hline $\mathrm{C} \times \mathrm{F}$ & 1.15 & - & - & - & - & - & - \\
\hline $\mathrm{C} \times \mathrm{E}$ & 3.45 & - & - & - & - & - & - \\
\hline $\mathrm{F} \times \mathrm{E}$ & 3.45 & - & - & - & - & - & - \\
\hline $\mathrm{C} \times \mathrm{F} \times \mathrm{E}$ & 3.45 & - & - & - & - & - & - \\
\hline
\end{tabular}


Table 3. Sentence-Medial Word ( $F$ Values for the ANOVAs at Lateral Electrodes)

\begin{tabular}{|c|c|c|c|c|c|c|c|}
\hline \multirow[b]{2}{*}{ Factors } & \multirow[b]{2}{*}{$d f$} & \multicolumn{6}{|c|}{ Latency Windows (msec) } \\
\hline & & $150-300$ & $300-450$ & $450-600$ & $600-750$ & $750-900$ & $900-1050$ \\
\hline $\mathrm{C}$ & 1.15 & - & - & $8.13 *$ & $19.04 * * *$ & $8.34 *$ & - \\
\hline $\mathrm{F}$ & 1.15 & - & - & - & - & - & - \\
\hline $\mathrm{C} \times \mathrm{F}$ & 1.15 & - & - & - & - & - & - \\
\hline $\mathrm{C} \times \mathrm{H}$ & 1.15 & - & - & - & - & - & - \\
\hline $\mathrm{F} \times \mathrm{H}$ & 1.15 & - & - & - & - & - & - \\
\hline $\mathrm{C} \times \mathrm{F} \times \mathrm{H}$ & 1.15 & - & - & - & - & - & - \\
\hline $\mathrm{C} \times \mathrm{L}$ & 2,30 & - & - & - & - & - & - \\
\hline $\mathrm{F} \times \mathrm{L}$ & 2,30 & - & - & - & - & - & - \\
\hline $\mathrm{C} \times \mathrm{F} \times \mathrm{L}$ & 2,30 & - & $4.33^{*}$ & $2.79^{\dagger}$ & $2.86^{\dagger}$ & - & - \\
\hline $\mathrm{C} \times \mathrm{H} \times \mathrm{L}$ & 2,30 & - & - & - & - & - & - \\
\hline $\mathrm{F} \times \mathrm{H} \times \mathrm{L}$ & 2,30 & - & - & - & - & - & - \\
\hline $\mathrm{C} \times \mathrm{F} \times \mathrm{H} \times \mathrm{L}$ & 2,30 & - & - & - & - & - & - \\
\hline
\end{tabular}

action were significant in any of the latency windows considered for analysis (see Tables 4 and 5).

\section{DISCUSSION}

Results of the experiment can be summarized as follows. First, clear differences are found between pragmatically congruous and incongruous prosodic patterns. Thus, prosodic cues seem to be processed on-line, in relation to their pragmatic relevance within the ongoing discourse context. Second, similar pragmatic congruity effects are found for both words with and without focal accents, with some slight differences. Finally, the pragmatic congruity effect is largely modulated by the posi-
Figure 4. Middle words. (A) Topographic maps of the pragmatic congruity effect in successive 150 -msec latency windows between 150 and $1050 \mathrm{msec}$ for words (A) with accents (mean amplitude differences between inappropriate $\left[{ }^{*} \mathrm{MF}_{0}\right]$ and expected $\left[\mathrm{MF}_{0}\right]$ focal accents) and (B) without focal accent (mean amplitude differences between missing [ $\left.{ }^{*} \mathrm{M}_{0} \mathrm{~F}\right]$ and expected no focal accents $\left.\left[\mathrm{M}_{0} \mathrm{~F}\right]\right)$.

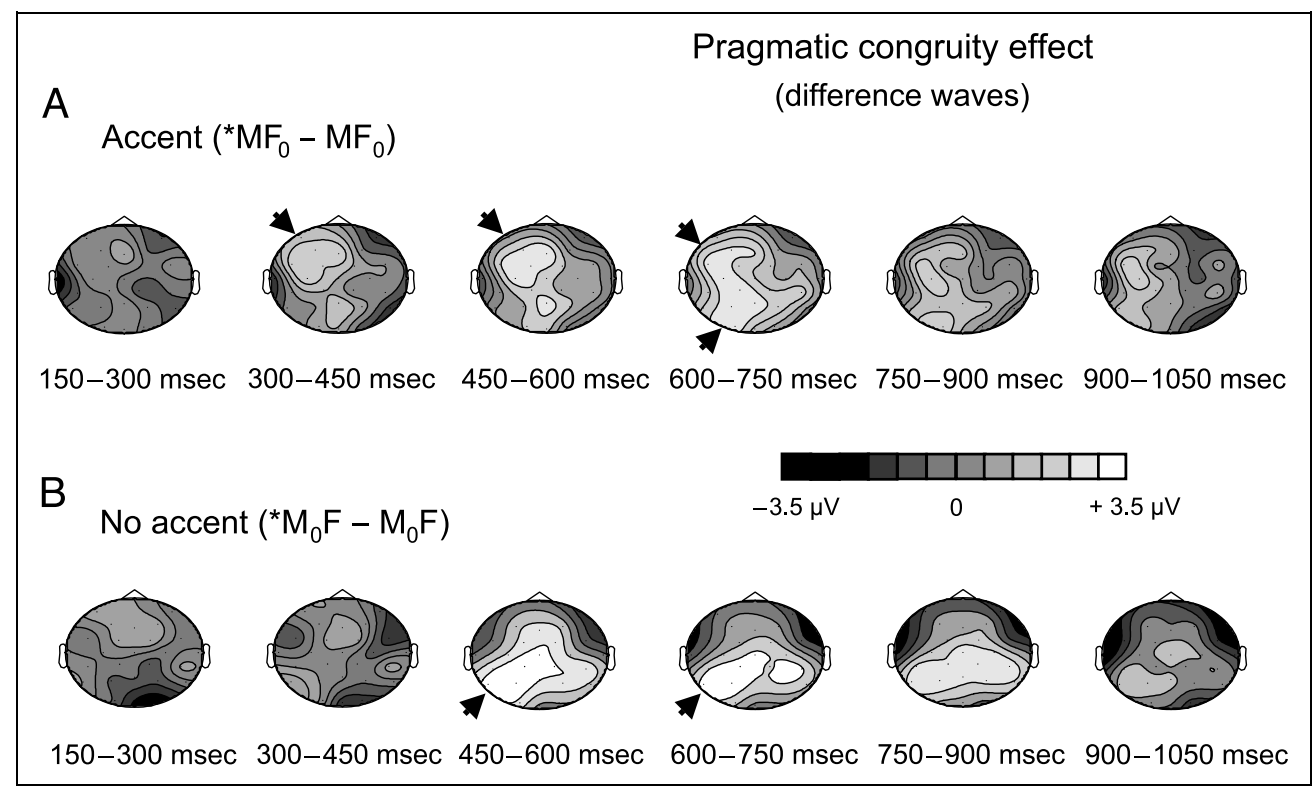


Figure 5. Pragmatic congruity effect for final words (A) with focal accents and (B) without focal accents. Effect of the presence/absence of focal accents for pragmatically (C) congruous and (D) incongruous prosodic patterns.

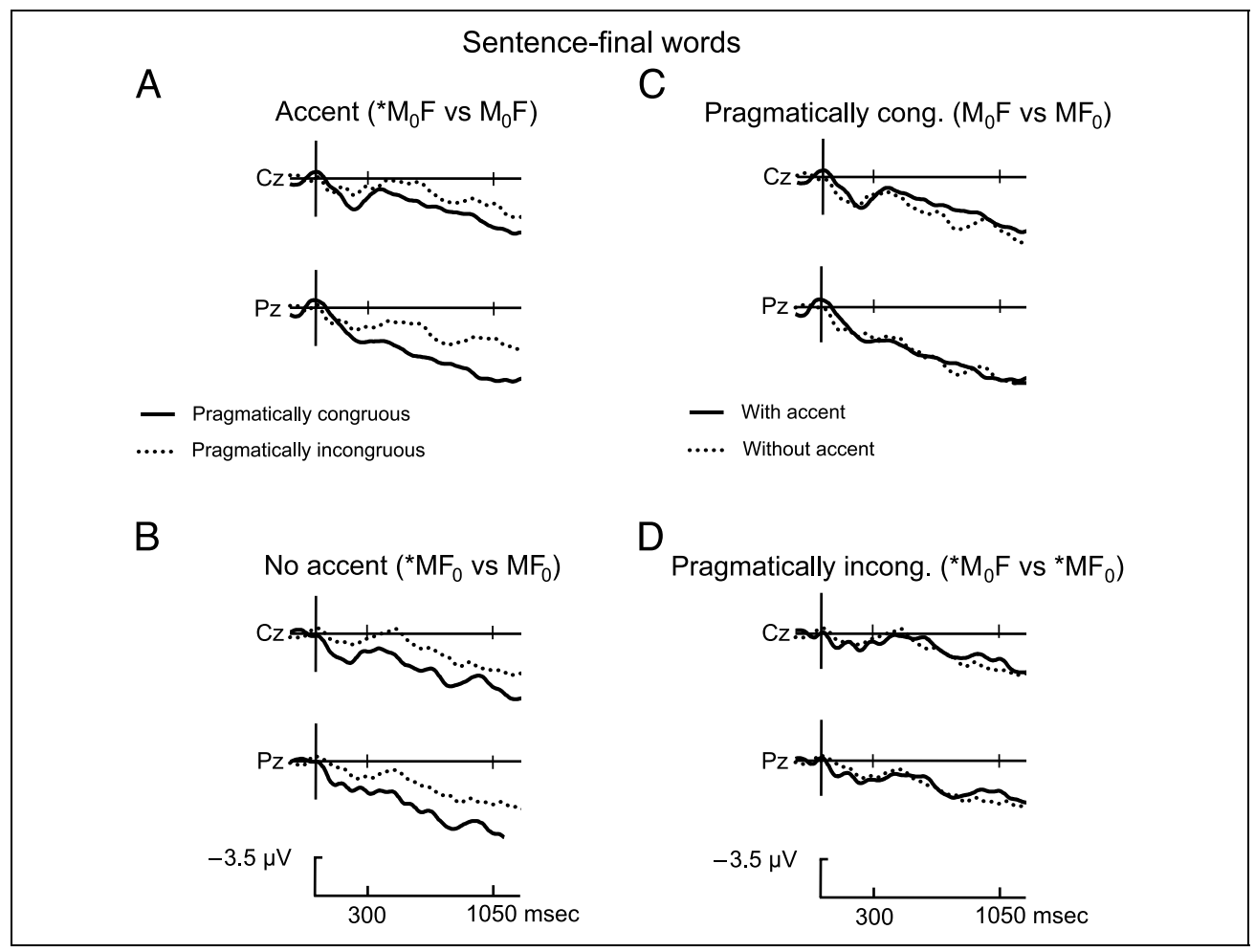

tion of incongruous prosodic patterns in the utterance: When they occur sentence medially, positive-going effects are elicited, whereas negative-going effects are elicited at the end of sentences. These results are discussed in turn, in light of previous results in the literature.

\section{On-line Processing of Contrastive Focus}

The present results clearly demonstrate that words with pragmatically incongruous prosodic patterns $\left({ }^{*} \mathrm{MF}_{0}\right.$ and $* \mathrm{M}_{0} \mathrm{~F}$ for sentence-medial words; $* \mathrm{M}_{0} \mathrm{~F}$ and $* \mathrm{MF}_{0}$ for final words) are associated with different ERP patterns compared with words with pragmatically congruous prosodic patterns $\left(\mathrm{MF}_{0}\right.$ and $\mathrm{M}_{0} \mathrm{~F}$ for sentence-medial words; $\mathrm{M}_{0} \mathrm{~F}$ and $\mathrm{MF}_{0}$ for final words). Thus, the very same focal accents (e.g., on the word ring $\left[\mathrm{MF}_{0}\right.$ and $\left.* \mathrm{MF}_{0}\right]$ or on the word fiancée $\left[\mathrm{M}_{0} \mathrm{~F}\right.$ and $\left.* \mathrm{M}_{0} \mathrm{~F}\right]$; see Table 1$)$ or the absence of such accents $\left(\mathrm{M}_{0} \mathrm{~F}\right.$ and ${ }^{*} \mathrm{M}_{0} \mathrm{~F}$; $\mathrm{MF}_{0}$ and $* \mathrm{MF}_{0}$ ) elicit different ERP patterns and are thereby processed differently, as a function of their pragmatic coherence within the ongoing dialogue context (see Figures 1A and 2A). Therefore, these results demonstrated that prosodic patterns are used on-line by

Table 4. Sentence-Final Word ( $F$ Values for the ANOVAs at Midline Electrodes)

\begin{tabular}{|c|c|c|c|c|c|c|c|}
\hline \multirow[b]{2}{*}{ Factors } & \multirow[b]{2}{*}{$d f$} & \multicolumn{6}{|c|}{ Latency Windows (msec) } \\
\hline & & $150-300$ & $300-450$ & $450-600$ & $600-750$ & $750-900$ & $900-1050$ \\
\hline C & 1.15 & $8.49 * *$ & $13.69 * *$ & $28.42 * * *$ & $29.75 * * *$ & $23.05 * * *$ & $14.59 * *$ \\
\hline $\mathrm{F}$ & 1.15 & - & - & - & - & - & - \\
\hline $\mathrm{C} \times \mathrm{F}$ & 1.15 & - & - & - & - & - & - \\
\hline$C \times E$ & 3.45 & $9.87 * * *$ & - & - & - & - & - \\
\hline $\mathrm{F} \times \mathrm{E}$ & 3.45 & - & - & - & - & - & - \\
\hline $\mathrm{C} \times \mathrm{F} \times \mathrm{E}$ & 3.45 & - & - & - & - & - & - \\
\hline
\end{tabular}


Table 5. Sentence-Final Word ( $F$ Values for the ANOVAs at Lateral Electrodes)

\begin{tabular}{|c|c|c|c|c|c|c|c|}
\hline \multirow[b]{2}{*}{ Factors } & \multirow[b]{2}{*}{$d f$} & \multicolumn{6}{|c|}{ Latency Windows (msec) } \\
\hline & & $150-300$ & $300-450$ & $450-600$ & $600-750$ & $750-900$ & $900-1050$ \\
\hline $\mathrm{C}$ & 1.15 & $3.56^{\dagger}$ & $4.30 *$ & $6.18^{*}$ & $5.97 *$ & $5.48 *$ & $4.69 *$ \\
\hline $\mathrm{F}$ & 1.15 & - & - & - & - & - & - \\
\hline $\mathrm{C} \times \mathrm{F}$ & 1.15 & - & - & - & - & - & - \\
\hline $\mathrm{C} \times \mathrm{H}$ & 1.15 & - & - & - & - & - & - \\
\hline $\mathrm{F} \times \mathrm{H}$ & 1.15 & - & - & - & - & - & - \\
\hline $\mathrm{C} \times \mathrm{F} \times \mathrm{H}$ & 1.15 & - & - & - & - & - & - \\
\hline $\mathrm{C} \times \mathrm{L}$ & 2,30 & - & - & - & - & $3.76^{*}$ & $5.93 * *$ \\
\hline $\mathrm{F} \times \mathrm{L}$ & 2,30 & - & - & - & - & - & - \\
\hline $\mathrm{C} \times \mathrm{F} \times \mathrm{L}$ & 2,30 & - & & & & - & - \\
\hline $\mathrm{C} \times \mathrm{H} \times \mathrm{L}$ & 2,30 & - & - & - & - & - & - \\
\hline $\mathrm{F} \times \mathrm{H} \times \mathrm{L}$ & 2,30 & - & - & - & - & - & - \\
\hline $\mathrm{C} \times \mathrm{F} \times \mathrm{H} \times \mathrm{L}$ & 2,30 & - & - & - & - & - & - \\
\hline
\end{tabular}

listeners to understand the informational structure of the message. In this respect, they extend those previously reported by Steinhauer et al. (1999), demonstrating that prosodic cues are processed on-line by the listeners to parse complex utterances.

By contrast, pragmatically congruous words with and without focal accents elicit similar patterns of brain waves (e.g., the word ring in the $\mathrm{MF}_{0}$ and $\mathrm{M}_{0} \mathrm{~F}$ con- ditions or the word fiancée in the $\mathrm{M}_{0} \mathrm{~F}$ and $\mathrm{MF}_{0}$ conditions; see Table 1 and Figures 3C and 5C). Similarly, words with inappropriate focal accents and with missing focal accents elicit similar overall ERP patterns ${ }^{4}$ (e.g., the word ring or the word fiancée in the $* \mathrm{M}_{0} \mathrm{~F}$ and $* \mathrm{MF}_{0}$ conditions, respectively; see Table 1 and Figures 3D and 5D). These results may seem somewhat surprising in light of detailed acoustic anal-
Figure 6. Final words. (A) Topographic maps of the pragmatic congruity effect in successive 150 -msec latency windows between 150 and $1050 \mathrm{msec}$ for words (A) with accents (mean amplitude differences between inappropriate $\left[{ }^{*} \mathrm{M}_{0} \mathrm{~F}\right]$ and expected $\left[\mathrm{M}_{0} \mathrm{~F}\right]$ focal accents), and (B) without focal accent (mean amplitude differences between missing $\left[{ }^{*} \mathrm{MF}_{0}\right]$ and expected no focal accents $\left.\left[\mathrm{MF}_{0}\right]\right)$.

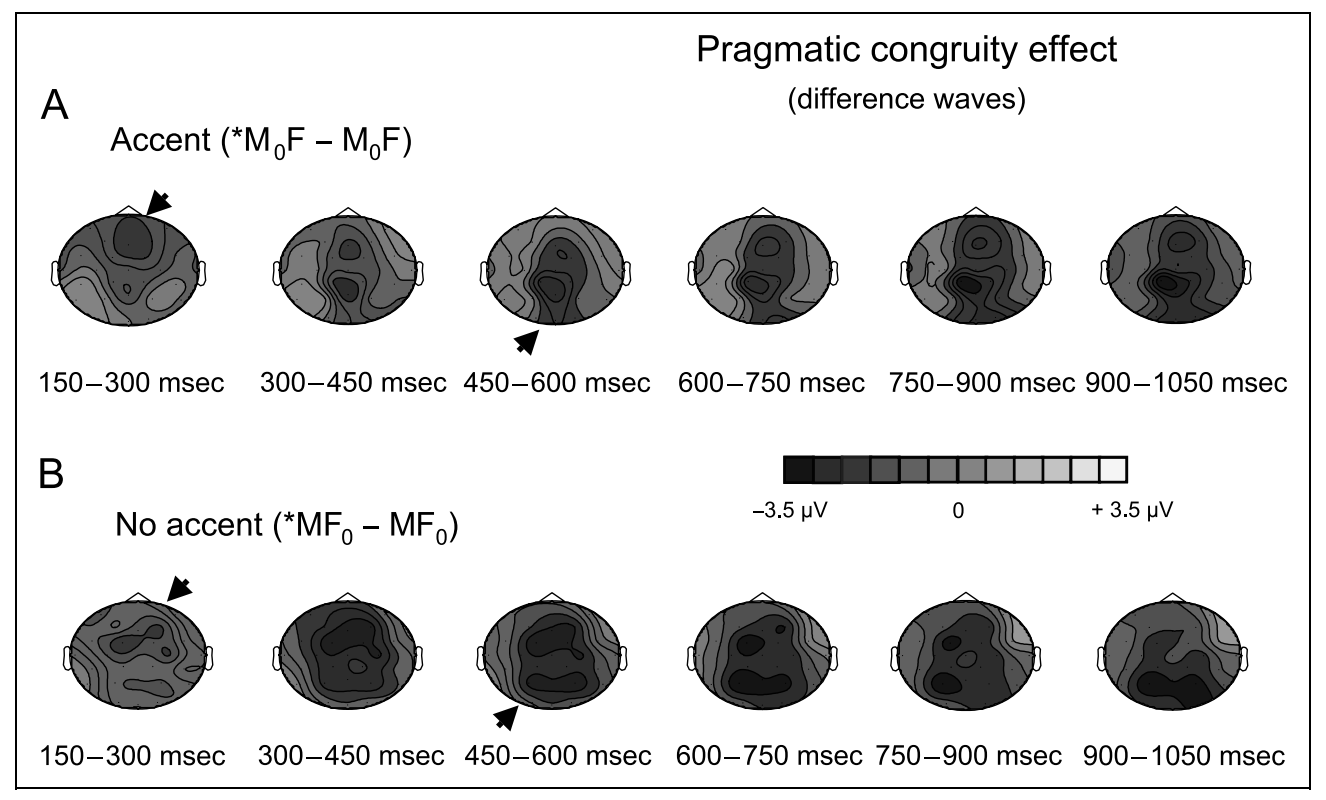


yses showing that, as found for contrastive focal accents in English (Selkirk, 2002), sentence-medial and -final words with focal contrastive accents are characterized by greater $\mathrm{F}_{0}$ and intensity values and longer duration than words with no focal accents (see Astésano, Magne, et al., 2004, for a more comprehensive presentation of these acoustic results). Thus, one could have expected such acoustic differences to influence the sensory, perceptual stages of spoken word processing and, as a consequence, to elicit differences in the N1-P2 exogenous ERP components. That this was not the case may result from a lack of sensitivity of the method or from overlap problems caused by the use of continuous speech. Note that another interpretation is to consider that the prosodic marking of focus is not as important as its derived pragmatic function. In other words, both words with and without focal accents may elicit similar patterns of brain waves whenever they are pragmatically appropriate or inappropriate within the sentence context. We tend to favor this last interpretation, which is in line with the point of view that in a discourse context the absence of focal accent on given information is as relevant as the presence of focal accent on new information. Thus, no utterance is neutral or unmarked in a discourse context (Sperber \& Wilson, 1986).

One may argue that the present results are specific to the present design because the material was built in such a way that participants came to expect focal contrastive accents in medial or final sentence positions (see the section Influence of Focal Contrastive Accent Position within the Utterance). This, however, was intentional. This first experiment sought to examine the explicit processing of prosodic cues and maximize the expectations derived from the context. To do so, we used question-answer pairs that, as shown by the results of several psycholinguistic experiments described in the Introduction, generate stronger contextual predictions than nonquestion contexts (Altmann, Garnham, van Nice, \& Henstra, 1998). Nevertheless, in future experiments it will be important to determine whether similar results are obtained when the design is built in such a way as to favor implicit processing of prosodic cues in dialogue contexts. ${ }^{5}$

\section{Relationship to Behavioral and Acoustic Experiments}

The present results are also in line with and extend those previously reported in psycholinguistic and experimental acoustics experiments aimed at better understanding the role of accentuation and intonation in spoken language processing. As mentioned in the introduction, results of several experiments have shown that accenting new/relevant information and de-accenting given/background information in the answers facilitate speech comprehension (Birch \& Clifton, 1995; Terken \&
Nooteboom, 1987; Bock \& Mazzella, 1983; Brown, 1983; Most and Saltz, 1979). One aim of the present study was to use an on-line measure of spoken language processing to enhance knowledge of the time course of such facilitatory influences.

As far as we know, only one study has contributed some information to this issue. Dahan, Tanenhaus, and Chambers (2002) used eye-movement recordings to examine auditory sentence comprehension processes as they unfold in real time. By combining the presentation of a visual scene with auditory instructions to move some of the objects in the scene, they were able to show that appropriate accentuation on the first syllable of a spoken target word allows the disambiguation of potentially ambiguous words. Thus, appropriate accentuation seems to affect comprehension at early stages of language processing. This conclusion is in line with our results showing that differences in the ERPs between pragmatically congruous and incongruous prosodic patterns started as early as 150-300 msec for final words and a little later (in the 300- to 450-msec range) for sentence-medial words.

Taken together, results gained from both off-line and on-line measures clearly point to the conclusion that accurate focal prominence realization on relevant/new information as well as the absence of such a cue on given information are used by listeners to process the informational structure of the discourse. In other words, the factor that seems to drive the pragmatic congruity of the answer is the appropriateness of relative prominences in the sentence. Note, however, that this is not to say that the given/new distinction is the only factor determining the position of focal prominences within an utterance. Indeed, ongoing research also highlights the importance of grammatical and thematic role assignments in the distribution of focal prominences (Venditti, Stone, Nanda, \& Tepper, 2002; Terken \& Hirscheberg, 1994). Future experiments will aim to examine the influence of these factors using on-line measures.

\section{Influence of Focal Contrastive Accent Position within the Utterance}

Interestingly, the pragmatic congruity effects reported here, including their onset latency, were largely modulated by the position of focal prominences in the utterance. The functional significance of the pragmatic effects for sentence-medial and final words is discussed in turn.

\section{Sentence-Medial Words}

Both types of pragmatically incongruous prosodic patterns, inappropriate $\left({ }^{*} \mathrm{MF}_{0}\right)$ and missing $\left({ }^{*} \mathrm{M}_{0} \mathrm{~F}\right)$ focal accents, elicited an increased positivity compared with expected focal accents $\left(\mathrm{MF}_{0}\right)$ or no accent expected $\left(\mathrm{M}_{0} \mathrm{~F}\right)$, from around $300 \mathrm{msec}$ until $1000 \mathrm{msec}$ (see the topographic maps illustrating the pragmatic congruity 
effect in Figure 4). Insofar as it may be surprising both to hear a focal accent when none is expected $\left({ }^{*} \mathrm{MF}_{0}\right)$ and not to hear a focal accent when one is expected $\left({ }^{*} \mathrm{M}_{0} \mathrm{~F}\right)$, the most likely interpretation is that the observed positivities reflect such a surprise effect and belong to the P300 family of components (Donchin, 1981). Moreover, based on the findings that neither the main effect of presence versus absence of focal accents nor the pragmatic congruity by focus interaction were significant in any of the latency bands considered for analysis, one could conclude that these positivities have the same functional significance for both words with and without focal accents. However, detailed analyses of the time course and scalp distribution of the pragmatic congruity effects for words with and without focal accents add important information in this respect.

In the 300- to 450-msec range, the pragmatic congruity effect was significant over frontal sites for words with focal accents $\left[\left({ }^{*} \mathrm{MF}_{0}\right)-\left(\mathrm{MF}_{0}\right)\right]$ but was not significant for words without accents (Congruity by presence/ absence of Focus by Localization interaction). Thus, the pragmatic congruity effect starts earlier for words with than without focal accents. By contrast, in the following successive 150-msec latency windows, from 450 to $900 \mathrm{msec}$, the pragmatic congruity effect is significant for both words with and without focal accents. Interestingly, however, this effect shows a frontal distribution for words with accents and a centroparietal distribution for words without accents in the 450- to 600 -msec range. Finally, the distribution of both pragmatic effects becomes more parietal in the latter latency band (600-700 msec). Taken together, both the time course and the scalp distribution of these pragmatic effects are strongly reminiscent of the $\mathrm{P} 3 \mathrm{a}$ and $\mathrm{P} 3 \mathrm{~b}$ components. Indeed, a large number of results in the ERP literature have demonstrated that novel and surprising events elicit an early frontally distributed positivity (P3a), whereas surprising and task-relevant events elicit a later centroparietally distributed positivity (P3b), whose latency varies with the difficulty of the categorization task (Picton, 1992; Duncan-Johnson \& Donchin, 1977; Kutas, MacCarthy, \& Donchin, 1977; see Donchin \& Coles, 1988, for a review). Therefore, a likely interpretation of the present data is that inappropriate accents, because of their unexpected acoustic characteristics (increase in $\mathrm{F}_{0}$ and intensity maxima and in duration), evoked an orientation response reflected in the early frontal P3a, which is not induced by words without focal accents, which are acoustically less salient. However, because both types of pragmatically incongruous prosodic patterns are task relevant, they evoke later parietally distributed P3b components.

One could argue, however, that the absence of $\mathrm{P} 3 \mathrm{a}$ components in response to missing accents is not caused by their less salient acoustic characteristics but rather by the fact that not having a focal contrastive accent on the word ring in the $* \mathrm{M}_{0} \mathrm{~F}$ condition could be of no surprise. Even without focal prominences, the answer may remain acceptable (pragmatically congruous) within the dialogue context (e.g., "Did he give his fiancée a ring or a bracelet?" "He gave a ring to his fiancée"). However, several authors have argued that this cannot be the case because words are always more or less prominent prosodically and that there are no accentless sentences in the European languages. Moreover, in our experiment, answers always had a focal accent either in sentence-medial or in sentence-final position. Therefore, the listeners always came to expect a focal accent. It remains, however, that not hearing an expected focal accent may not be as surprising as hearing an inappropriate focal accent. Consequently, no $\mathrm{P} 3 \mathrm{a}$ is generated, but because the lack of accent remains unexpected and task relevant, a P3b component is generated. Interestingly, Bornkessel, Schlesewsky, and Friederici (2003) recently showed that focused constituents also elicit increased positivities that are functionally similar to the P3b component.

\section{Sentence-Final Words}

Both types of incongruous prosodic patterns, inappropriate $\left({ }^{*} \mathrm{M}_{0} \mathrm{~F}\right)$ and missing accents $\left({ }^{*} \mathrm{MF}_{0}\right)$, elicited overall more negative-going ERPs, from around $100 \mathrm{msec}$ until the end of the recording period, than final words with pragmatically congruous prosodic patterns $\left(\mathrm{M}_{0} \mathrm{~F}\right.$ and $\mathrm{MF}_{0}$; see Figures 2 and 6). In the 300- to 600-msec latency band, these negativities, in their latency and scalp distribution, resemble the N400 component described in several previous auditory sentence experiments (e.g., Holcomb \& Neville, 1990; McCallum, Farmer, \& Pocock, 1984). Typically, the N400 component is elicited by words that do not fit semantically within the context of another word, a sentence, or a larger discourse and is generally interpreted as reflecting semantic integration processes (see Besson, Magne, \& Regnault, 2004; Brown \& Hagoort, 1999, for reviews). It is also interesting to note that an N400 component has also been found in some experiments to semantically congruous words in sentence-final positions when semantic or syntactic violations occurred earlier in the sentence (Osterhout \& Nicol, 1999; Hagoort, Brown, et al., 1993; Osterhout \& Holcomb, 1992, 1993).

Studying the interplay between semantic and syntactic processing, Hagoort (2003), for instance, conducted an experiment in which participants were asked to judge the overall acceptability of sentences containing syntactic, semantic, or combined violations. Moreover, these syntactic and/or semantic incongruities could occur either in middle or in final sentence positions. Interestingly, results revealed that when semantic or syntactic violations occurred sentence medially, sentence-final words were associated with larger N400 components than when no such violation occurred. Hagoort (2003) interprets these findings as suggesting that some addi- 
tional processing was necessary at the end of the sentence when syntactic and/or semantic violations occurred earlier in the sentence.

Along the same lines, our results may reflect additional processing at the end of the sentence, which is necessary to solve the integration processing problems that stem from the presence of pragmatically incongruous prosodic patterns in middle sentence position. Although we tend to favor this interpretation, two other explanations need to be considered. First, one may argue that inappropriate and missing focal accents always elicit positivities independently of their position in the sentence. At the end of the sentences, however, integration processes of the type described above may be necessary to build up a coherent representation of the informational structure of the dialogue. Such integration processes would be reflected by an increased negativity that may overlap, and thus mask, the positivity elicited by final pragmatically incongruous prosodic patterns.

Second, pragmatic incongruities in final position are clearly not as surprising as in the middle of the sentence. Indeed, the material was built in such a way that when a focal accent was missing in the final position of the sentence, an inappropriate focal accent had always occurred in sentence-medial position. In the same way, when an inappropriate focal accent was present in sentence-final position, a focal accent was missing in sentence-medial position. Thus, in both cases, the occurrence of pragmatically incongruous prosodic patterns in sentence-final position was less surprising because it could be anticipated from the nature of the prosodic patterns heard sentence medially. Such anticipation processes are known to be reflected by slow negative waves like the contingent negative variation (CNV, Walter, Cooper, Aldridge, McCallum, \& Winter, 1964). Therefore, it is possible that as soon as participants hear focus violations in sentence-medial position, a CNV develops, reflecting the expectation that a focus violation will also occur at sentence-final position. This would also explain why the pragmatic congruity effect starts earlier for sentence-final than -medial words.

To summarize, in sentence-medial position, pragmatically incongruous prosodic patterns (missing or inappropriate focal accents) elicited positive components (P3a and $\mathrm{P} 3 \mathrm{~b}$ ) that seem to be related to the processing of surprising and task-relevant prosodic patterns. By contrast, in sentence-final position, pragmatically incongruous prosodic patterns elicited negativities that may reflect the integration difficulties encountered in extracting the overall informational structure of the sentence. It should be kept in mind, however, that the results for focus violations in sentence-final position are being influenced by the fact that these sentences also contained violations in sentence-medial position. Thus, they may also reflect the occurrence of a CNV-like component.
In conclusion, the present results clearly demonstrate the psychobiological validity of the pragmatic concept of focus. They strongly support the hypothesis that prosodic cues allow us to distinguish new/relevant from given information in the particular context of the utterance (Fowler \& Housum, 1987). In this regard, the present results are important for linguistic functionalist theories emphasizing the role of prosodic information in discourse comprehension (Lambrecht, 1994; Chafe, 1987; Halliday, 1985; Prince, 1981; Dik, 1978, 1997; Firbas, 1964; see Prévost, 2001, for a comprehensive review).

\section{METHODS}

\section{Participants}

Sixteen participants ( 9 women, 24-28 years old, mean, 25.2 years) were paid to participate in the experiment, which lasted for about $2 \mathrm{hr}$. All were right-handed native speakers of French with no hearing problems.

\section{Stimuli}

We constructed 240 dialogues composed of a question followed by an answer. Half of the questions generated expectancies for contrastive focal accents on the middle word of the answer and the other half on the final word of the answer (see Table 1). By manipulating the congruency of the position of focal accents on middle or on final words in the answers relative to the expectancy generated by the question, the design consisted of four experimental conditions $\left(\mathrm{MF}_{0}, * \mathrm{MF}_{0}, \mathrm{M}_{0} \mathrm{~F}\right.$, and $\left.* \mathrm{M}_{0} \mathrm{~F}\right)$. Furthermore, this design allowed us to examine the effect of the absence of focal accents when none is expected compared with when one is expected (see Table 1).

To introduce variability in the dialogues, questions were spoken by three male speakers (two men for 134 and 92 recordings, respectively, and one child for the most naive questions, i.e., 14 recordings). By contrast, the 240 answers were always spoken by the same female speaker to preserve a desirable homogeneity of the realization of the contrastive focal accents. Moreover, words with contrastive focal accents, whether in middle or final sentence positions, were always nouns. Finally, four different lists of dialogues were built (Latin square design), so that one participant never listened to the same question-answer pair more than once, but all the question-answer pairs were presented in all four conditions across participants. Within a list, 120 dialogues were selected from the pool of 240 dialogues: 60 dialogues were coherent (30 with congruous contrastive focal accent on middle words and 30 with congruous contrastive focal accent on final words; expected focal accent) and 60 were incoherent (30 with incongruous contrastive focal accent on middle words and 30 with incongruous contrastive focal accent on final words; 
inappropriate focal accent). The second list was built using the 120 dialogues that were not presented in the first list. Finally, the other two lists were derived from the first and the second lists by replacing all coherent dialogues by their incoherent counterparts and vice versa.

\section{Speech Signals}

Dialogues were recorded in a soundproof acoustic studio on a computer using an AP-850 Galaxy microphone and a SoundBlaster NCV 128 card, allowing $22050 \mathrm{~Hz}$ and 16-bit sampling rate. For the recording and clipping of the acoustic signals, we used a homemade recording and signal analysis software, Kparole, which is part of a larger research project of speech synthesis called Kali (Morel \& Lacheret, 2001). Acoustic analyses were conducted using the signal analysis software MES developed in Aix-en-Provence (Espesser, 1996). Four independent judges carefully listened to the recordings to control for naturalness of the intonation and to detect recording noises as well as to ensure that the meaning and the syntactic structure of the sentences could be easily understood.

\section{Acoustic Analyses}

For each of the 240 answers, the acoustic signal corresponding to the middle and final target words was segmented by hand. The fundamental frequency $\left(\mathrm{F}_{0}\right)$ was modeled with a quadratic spline function using an automatic modeling algorithm with manual corrections (Momel, Hirst \& Espesser, 1993). Whole word duration (milliseconds), as well as intensity (decibels) and $\mathrm{F}_{0}$ (hertz) maximum values were analyzed for each target word of the answers. Intensity maxima were normalized with respect to the mean intensity value of each answer to suppress loudness differences between each recording. Table 6 presents the results for the acoustic measures in middle and final words. Three one-way ANOVAs were performed for middle and final words separately, with word duration, intensity, and $\mathrm{F}_{0}$ maxima as dependent variables and focal versus no focal accents as independent variables. Results indicate that both middle and final words with focal accents showed significantly higher $\mathrm{F}_{0}$ and intensity maxima as well as longer duration overall than words without focal accents (Table 6; see Astésano, Magne, et al., 2004, for a more comprehensive presentation of these acoustic results). Focus onset was determined by comparing the two versions of the sentences, with and without focal accents. The time when the intensity and $\mathrm{F}_{0}$ values started to differ in these two conditions was taken as focus onset. On average, results showed that focus onset was located 79 msec after word onset with a standard deviation of 54 msec.

\section{Procedure}

Participants were seated in a comfortable chair in an electrically shielded room, facing a computer screen. A total of 120 dialogues were presented auditorily through headphones, in three blocks of 40 trials. The timing within each trial was as follows: Each dialogue started with a question, followed by an answer after a silence of $700 \mathrm{msec}$ (mean duration of a dialogue, $4 \mathrm{sec}$ ). One second after the offset of the answer, a fixation cross appeared on the computer screen for $2 \mathrm{sec}$, and participants gave their responses (Figure 7). They were required to judge whether the intonation of the answer was coherent or not in relation to the question. They responded by pressing one of two response keys (for "Yes" or "No" responses); the hand of response was counterbalanced across participants. To avoid spurious effects linked to the order of presentation, the questionanswer pairs were presented in a pseudorandom order (no more than three dialogues of the same experimental condition presented in succession). The order of presentation varied from one participant to the other. Each session began with a practice session to familiarize participants with the task and train them to blink during the interstimulus interval (ISI).

\section{ERP Recordings}

Because we were interested in the precise time course of focus processing and because focal accent onset slightly varies from one focused word to the other, electroencephalogram (EEG) acquisition was synchronized to the onset of focal accents rather than to the onset of the word. EEG was recorded for $2150 \mathrm{msec}$

Table 6. Acoustic Analyses for Sentence-Medial and Sentence-Final Words

\begin{tabular}{|c|c|c|c|c|c|c|}
\hline & \multicolumn{3}{|c|}{ Sentence-Medial Word } & \multicolumn{3}{|c|}{ Sentence-Final Word } \\
\hline & Accent & No Accent & $F(1,238)$ & Accent & No Accent & $F(1,238)$ \\
\hline Duration (msec) & 606 & 465 & $76.35 * * *$ & 619 & 531 & $17.70 * * *$ \\
\hline $\mathrm{F}_{0} \operatorname{maxima}(\mathrm{Hz})$ & 246 & 228 & $34.58 * * *$ & 231 & 157 & $1090.20 * * *$ \\
\hline Intensity maxima (normalized dB) & 5.5 & 4.1 & $54.14 * * *$ & 5.7 & 4.5 & $47.31 * * *$ \\
\hline
\end{tabular}

$* * * p<.001$. 
Figure 7. Timing within a trial. Each dialogue started with a question followed by an answer after a silence of $700 \mathrm{msec}$. One second after the offset of the answer, a fixation cross appeared on the computer screen for $2 \mathrm{sec}$, and participants were required to give their responses. EEG was recorded for 2,150 msec, starting 150 msec before focal accent onset on medial (M) or final words $(F)$.

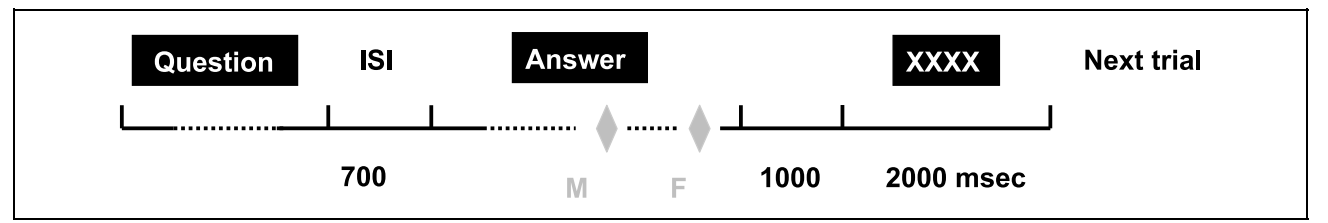

(Figure 7), starting $150 \mathrm{msec}$ before focal accent onset on middle or final words from 28 scalp electrodes mounted on an elastic cap and located at standard leftand right-hemisphere positions over frontal, central, parietal, occipital, and temporal areas (International 10/20 system sites: Fz, Cz, Pz, Oz, Fp1, Fp2, F3, F4, C3, C4, P3, P4, O1, O2, F7, F8, T3, T4, T5, T6, Fc5, Fc1, Fc2, Fc6, Cp5, Cp1, Cp2, and Cp6).

These recording sites plus an electrode placed on the right mastoid were referenced to the left mastoid electrode. The data were then re-referenced off-line to the algebraic average of the left and right mastoids. Impedances of the electrodes never exceeded $3 \mathrm{k} \Omega$. To detect vertical eye movements and blinks, the horizontal electrooculogram (EOG) was recorded from electrodes placed $1 \mathrm{~cm}$ to the left and right of the external canthi, and the vertical EOG was recorded from an electrode beneath the right eye, referenced to the left mastoid. Trials containing ocular artifacts, movement artifacts, or amplifier saturation were excluded from the averaged ERP waveforms. The EEG and EOG were amplified by an SA Instrumentation (San Diego, CA) amplifier with a band pass of $0.01-30 \mathrm{~Hz}$, and were digitized at $250 \mathrm{~Hz}$ by a PC-compatible microcomputer.

\section{Acknowledgments}

This research was supported by a grant from the Human Frontier Science Program (HSFP RGP0053) to Mireille Besson (PI), Régine Kolinsky, Isabelle Peretz, and Kai Alter. The collaboration between Mireille Besson, Anne Lacheret, and Michel Morel was supported by the French Ministry of Research (Action Concertée Incitative "Approche pluridisciplinaire de la complexité linguistique: spécificités et interactions entre les niveaux structurels du langage" organized by Stéphane Robert). Cyrille Magne benefited from a Cognitive Science fellowship from the French Ministry of Research, and Corine Astésano is a postdoctorate researcher supported by a grant from HFSP. The authors gratefully acknowledge Stéphane Robert, Bernard Victorri, and two anonymous reviewers for their helpful and constructive comments and Monique Chiambretto and Reyna Leigh Gordon for their technical assistance.

Reprint requests should be sent to Cyrille Magne, Center for Complex Systems \& Brain Sciences, Florida Atlantic
University, 777 Glades Road, Boca Raton, FL 33431, or via e-mail:magne@ccs.fau.edu.

\section{Notes}

1. Note that the word "ring" brings the relevant information not because this is a new word (it is already introduced in the question), but because the relation between the word ring and the context (i.e., John gave something to his fiancée) is new.

2. In pragmatic theories, the cognitive pair ground/figure may receive different labels such as given/new, topic/focus, theme/rheme, theme/predicate, topic/comment, and so on (see Fuchs \& Marchello-Nizia, 1998, for a presentation). All of them can be used synonymously. However, as noted by Venditti and Hirschberg (2003), although these concepts are widely used because they are intuitively understood, they nevertheless remain extremely difficult to define.

3. Because we were interested in the processing of focal accent, ERP recordings were time locked to focal accent onset, which is the moment when the acoustic analyses show that the $\mathrm{F}_{0}$ and intensity values for words with and without accents start to differ (see Methods).

4. We also found some early interesting differences in the pragmatic congruity effect for sentence-medial words with or without focal accents; these results are discussed below, in the section Influence of Focal Contrastive Accent Position within the Utterance.

5. One could also argue that different results would be obtained if comparisons were made relative to a control condition in which no contrastive focal accents were expected. However, such a control condition was not included for the two following reasons. First, at least for words in middlesentence position, the condition in which there is no focal accent and none is expected $\left(\mathrm{M}_{0} \mathrm{~F}\right)$ seems like a good control for both conditions in which there is a focal accent that is either pragmatically congruous $\left(\mathrm{MF}_{0}\right)$ or incongruous $\left({ }^{*} \mathrm{MF}_{0}\right)$. Second, for such a control condition to play its role, as many control as experimental dialogues would be needed. This would have considerably increased both the difficulty of constructing the linguistic materials and the duration of the experiment.

\section{REFERENCES}

Altmann, G. T. M., Garnham, A., van Nice, K., \& Henstra, J. A. (1998). Late closure in context. Journal of Memory and Language, 38, 459-484. 
Astésano, C. (2001). Rythme et accentuation en français. Invariance et variabilité stylistique. Paris: L'Harmattan.

Astésano, C., Besson, M., \& Alter, K. (2004). Brain potentials during semantic and prosodic processing in French. Cognitive Brain Research, 18, 172-184.

Astésano, C., Magne, C., Morel, M., Coquillon, A., Espesser, R., Besson, M., \& Lacheret, A. (2004). Marquage acoustique du focus contrastif non codé syntaxiquement en français. Actes des XXVièmes Journées d'Etudes sur la parole (pp. 126-129). Fez, Morocco: Université de Provence, Aix-en Provence.

Besson, M., Magne, C., \& Regnault, P. (2004). Le traitement du langage. In B. Renault (Ed.), L'imagerie fonctionnelle électrique (EEG) et magnétique (MEG): Ses applications en sciences cognitives. Paris: Hermés.

Besson, M., Magne, C., \& Schön, D. (2002). Emotional prosody: Sex differences in sensitivity to speech melody. Trends in Cognitive Sciences, 6, 405-407.

Birch, S., \& Clifton, C. E. (1995). Focus, accent, and argument structure: Effects on language comprehension. Language and Speech, 38, 365-391.

Bock, J. K., \& Mazzella, J. R. (1983). Intonational marking of given and new information: Some consequences for comprehension. Memory and Cognition, 11, 64-76.

Böcker, K. B. E., Bastiaansen, M. C. M., Vroomen, J., Brunia, C. H. M., \& De Gelder, B. (1999). An ERP correlate of metrical stress in spoken word recognition. Psychophysiology, 36, 706-720.

Bornkessel, I., Schlesewsky, M., \& Friederici, A. D. (2003). Contextual information modulates initial processes of syntactic integration: The role of inter- versus intrasentential predictions. Journal of Experimental Psychology: Learning Memory and Cognition, 29, 871-882.

Brown, C., \& Hagoort, P. (1999). On the electrophysiology of language comprehension: Implications for the human language system. In M. Crocker, M. Pickering, \& C. Clifton (Eds.), Architectures and mechanisms for language processing (pp. 213-237). Cambridge: Cambridge University Press.

Brown, G. (1983). Prosodic structure and the given/new distinction. In D. R. Ladd \& A. Cutler (Eds.), Prosody: Models and measurements (pp. 67-78). Berlin: Springer.

Chafe, W. L. (1987). Cognitive constraints of information flow. In R. S. Tomlin (Ed.), Coherence and grounding in discourse, typological studies in language (Vol. 11, pp. 21-51). Amsterdam: John Benjamins.

Cutler, A., Dahan, D., \& van Donselaar, W. (1997). Prosody in the comprehension of spoken language: A literature review. Language and Speech, 40, 141-201.

Dahan, D., Tanenhaus, M. K., \& Chambers, C. G. (2002). Accent and reference resolution in spoken-language comprehension. Journal of Memory and Language, 47, 292-314.

Di Cristo, A. (1998). French. In D. Hirst \& A. Di Cristo (Eds.), Intonation systems: A survey of twenty languages (pp. 195-218). Cambridge: Cambridge University Press.

Di Cristo, A. (1999). Le cadre accentuel du français contemporain: Essai de modélisation (1ère partie). Langues, 2, 184-205.

Dik, S. (1978). Functional grammar. Dordrecht: Foris.

Dik, S. (1997). The theory of functional grammar. Berlin: De Gruyter.

Donchin, E. (1981). Surprise! ... Surprise? Psychophysiology, 18, 493-513.

Donchin, E., \& Coles, M. G. H. (1988). Is the P300 component a manifestation of context-updating? Behavioural and Brain Sciences, 11, 355-372.
Duncan-Johnson, C., \& Donchin, E. (1977). On quantifying surprise, the variation of event-related potentials with subjective probability. Psychophysiology, 14, 456-467.

Espesser, R. (1996). MES: Un environnement de traitement du signal. Actes des XXIièmes Journées d'Etudes sur la parole (p. 447). Avignon.

Fauconnier, G. (1984). Espaces mentaux. Paris: de Minuit.

Firbas, J. (1964). On defining the theme in functional sentence analysis. Travaux Linguistiques de Prague, 1, 267-280.

Fodor, J. D. (2002). Psycholinguistics cannot escape prosody. Proceedings of the 1st International Conference on Speech Prosody (pp. 83-88). Aix-en Provence: Université de Provence.

Fowler, C. A., \& Housum, J. (1987). “Talkers" signaling of "New" and "Old" words in speech and listeners' perception and use of the distinction. Journal of Memory and Language, 26, 489-504.

Friedrich, C. K., Alter, K., \& Kotz, S. A. (2001). An electrophysiological response to different pitch contours in words. NeuroReport, 12, 3189-3191.

Fuchs, C., \& Marchello-Nizia, C. (1998). Les opérations de thématisation en français. Cahiers de praxématique. Montpellier: Praxiling.

Gunter, T. C., Stowe, L. A., \& Mulder, G. (1997). When syntax meets semantics. Psychophysiology, 34, 660-676.

Hagoort, P. (2003). Interplay between syntax and semantics during sentence comprehension: ERP effects of combining syntactic and semantic violations. Journal of Cognitive Neuroscience, 15, 883-899.

Hagoort, P., Brown, C. M., \& Groothusen, J. (1993). The syntactic positive shift (SPS) as an ERP measure of syntactic processing. Language and Cognitive Processes, 8, 439-483.

Hahne, A., \& Friederici, A. D. (1999). Electrophysiological evidence for two steps in syntactic analysis. Early automatic and late controlled processes. Journal of Cognitive Neuroscience, 11, 194-205.

Halliday, M. A. K. (1985). Spoken and written language. Oxford: Oxford University Press.

Hirst, D. J., \& Di Cristo, A. (1998). A survey of intonation systems. In D. J. Hirst \& A. Di Cristo (Eds.), Intonation systems : A survey of twenty languages (pp. 1-44). Cambridge: Cambridge University Press.

Hirst, D. J., \& Espesser, R. (1993). Automatic modelling of fundamental frequency using a quadratic spline function, Travaux de l'Institut de Pbonetique d'Aix, 15, $71-85$.

Holcomb, P. J., \& Neville, H. (1990). Auditory and visual semantic priming in lexical decision: A comparison using event-related brain potentials. Language and Cognitive Processes, 5, 281-312.

Kutas, M., \& Hillyard, S. A. (1980). Reading senseless sentences: Brain potentials reflect semantic incongruity. Science, 207, 203-205.

Kutas, M., McCarthy, G., \& Donchin, E. (1977). Augmenting mental chronometry: The P300 as a measure of stimulus evaluation time. Science, 197, 792-795.

Lacheret-Dujour, A., \& Beaugendre, F. (1999). La prosodie du français. Paris: CNRS.

Ladd, D. R. (1980). The structure of intonational meaning, Bloomington: Indiana University Press.

Ladd, D. R. (1991). Integrating syntagmatic and paradigmatic aspects of stress. Actes du 12ème Congrès International des Sciences Phonétiques (pp. 283-287). Aix-en-Provence, France: Université de Provence.

Lambrecht, K. (1994). Information structure and sentence form: Topic, focus and the mental representations of 
discourse referents. Cambridge studies in linguistics (Vol. 71). Cambridge: Cambridge University Press.

McCallum, W. C., Farmer, S. F., \& Pocock, P. V. (1984). The effects of physical and semantic incongruities on auditory event-related potentials. Electroencephalography and Clinical Neurophysiology, 59, 477-488.

Morel, M., \& Lacheret, A. (2001). Kali, synthèse vocale à partir du texte: De la conception à la mise en oeuvre. In Ch. D'Alessandro (Ed.), Traitement automatique des langues, synthèse de la parole à partir du texte (Vol. 42, pp. 193-221). Paris: Hermès.

Most, R. B., \& Saltz, E. (1979). Information structure in sentences: New information. Language and Speech, 22, 89-95.

Osterhout, L. (1997). On the brain response to syntactic anomalies: Manipulations of word position and word class reveal individual differences. Brain and Language, 59, 494-522.

Osterhout, L., \& Holcomb, P. J. (1992). Event-related brain potentials elicited by syntactic anomaly. Journal of Memory and Language, 31, 785-804.

Osterhout, L., \& Holcomb, P. J. (1993). Event-related potentials and syntactic anomaly: Evidence of anomaly detection during the perception of continuous speech. Language and Cognitive Processes, 8, 413-437.

Osterhout, L., \& Nicol, J. (1999). On the distinctiveness, independence, and time course of the brain responses to syntactic and semantic anomalies. Language and Cognitive Processes, 14, 283-317.

Pasdeloup, V. (1990). Modèle de règles rythmiques du français appliqué à la synthèse de la parole. Ph.D. thesis, Université de Provence, Marseille, France.

Picton, T. W. (1992). The P300 wave of the human event-related potential. Journal of Clinical Neurophysiology, 9, 456-479.

Prévost, P. (2001). La variabilité morphologique en français langue seconde. Langues et linguistique, 27, 1-28.

Prince, E. F. (1981). Toward a taxonomy of given-new information. In P. Cole (Ed.), Radical pragmatics (pp. 223-255). New York: Academic Press.

Schirmer, A., Kotz, S. A., \& Friederici, A. D. (2002). Sex differentiates the role of emotional prosody during word processing. Cognitive Brain Research, 14, 228-233.
Séguinot, A. (1976). L'accent d'insistance en français standard. Studia Phonetica, 12, 1-58.

Selkirk, E. (2002). Contrastive FOCUS vs. presentational focus: Prosodic evidence from right node raising in English. Proceedings of the 1st International Conference on Speech Prosody (pp. 643-646). Aix-en-Provence, France: Université de Provence.

Sperber, D., \& Wilson, D. (1986). La pertinence. Paris: de Minuit.

Steinhauer, K., Alter, K., \& Friederici, A. D. (1999). Brain potentials indicate immediate use of prosodic cues in natural speech processing. Nature Neuroscience, 2, 191-196.

Steinhauer, K., \& Friederici, A. D. (2001). Prosodic boundaries, comma rules, and brain responses: The closure positive shift in ERPs as a universal marker for prosodic phrasing in listeners and readers. Journal of Psycholinguistic Research, 30, 267-295.

Terken, J., \& Hirscheberg, J. (1994). Deaccentuation of words representing "given" information: Effects of persistence of grammatical function and surface position. Language and Speech, 37, 125-145.

Terken, J., \& Nooteboom, S. G. (1987). Opposite effects of accentuation and deaccentuation on verification latencies for given and new information. Language and Cognitive Processes, 2, 145-163.

Van Petten, C., \& Kutas, M. (1990). Interactions between sentence context and word frequency in event-related brain potentials. Memory and Cognition, 18, 380-393.

Venditti, J. J., \& Hirschberg, J. (2003). Intonation and discourse processing. Proceedings of the international congress of phonetic sciences (pp. 315-318). Barcelona, Spain: Universitat Autonoma de Barcelona.

Venditti, J. J., Stone, M., Nanda, P., \& Tepper, P. (2002). Discourse constraints on the interpretation of nuclear-accented pronouns. Proceedings of speech prosody (pp. 83-88). Aix-en-Provence, France: Université de Provence.

Walter, W. G., Cooper, R., Aldridge, V. J., McCallum, W. C., \& Winter, A. L. (1964). Contingent negative variation: An electrical sign of sensorimotor association and expectancy in the human brain. Nature, 203, 380-384. 